\title{
Evaluation of Cutting Performance of Alumina-Graphene Composite Ceramic Tool
}

\author{
K.I.Vishnu Vandana ${ }^{1}$, Dr K.N.S.Suman ${ }^{2}$ \\ ${ }^{1}$ Assistant Professor, Department of Mechanical Engineering, Prasad V Potluri Siddhartha Institute of \\ Technology, Vijayawada. Email: Vandana.k@pvpsiddhartha.ac.in \\ ${ }^{2}$ Associate professor, Department of Mechanical Engineering, Andhra University, Vishakhapatnam.
}

\begin{abstract}
In this paper, an attempt is made to enhance the Alumina ceramic cutting tool performance after reinforcing it with nano graphene particles $(0.35 \mathrm{wt} \%$ and $0.45 \mathrm{wt} \%)$, which are fabricated by employing powder metallurgy route. The performance of the prepared Alumina - Graphene ceramic composite cutting tools are studied by observing the abrasive wear behavior of tools during machining of two different work piece materials, namely EN24 and EN36 steels, respectively. The influence of different cutting parameters like speed, feed, depth of cut on abrasive wear of the prepared tool inserts are examined. Further, the machining characteristic of prepared cutting tool inserts in terms of surface finish of machined components is also studied. The experimental outcome revealed the fact that the ceramic cutting tools reinforced with nano graphene particles have exhibited better cutting performance and enhanced the quality of the machined work piece.
\end{abstract}

Key words: Alumina-graphene, composite ceramic tool, abrasive wear, cutting performance.

\section{INTRODUCTION}

Selection of right tool for right manufacturing operation is the key step in fabricating an effective component used for a specific purpose. But the selection of tool material mainly depends on the operations to be performed on the work piece and material of the work piece. At the same time there are several alternative choices for the tool materials in order to produce parts successfully. The power rating, range of speeds and rigidity of the machine tools, productivity demands and tooling budget limitations are some of the vital factors to be considered in the selection of appropriate tools for machining. Under such scenarios, the last three decades had seen the usage of ceramics in different applications ${ }^{[1,2]}$ including as a tool material on account of their great protection from oxidation, moderately high hardness and low coefficient of friction. Especially ceramic materials, like $\mathrm{Al}_{2} \mathrm{O}_{3}$, are considered as competition for regular tool materials to machine hardened

steels. ${ }^{[3]}$ These hardened steels are generally used in highly and cyclically loaded machine parts. Alumina being an attractive ceramic material was used as cutting tool for high temperature and high speed machining operations since a long time. These tools are also used to obtain quality surface finish by turning the hard working materials. ${ }^{[4]}$ At the same time they had also shown a better cutting performance in terms of increased metal removal rate when compared with the conventional tools did in hard turning. ${ }^{[5]}$ Apart from good machining performance, ceramic cutting tools also impart better surface finish to the machined surfaces even when compared with commercial cutting tools. ${ }^{[6]}$ In spite of its good chemical inertness and high hardness, the deprived fracture toughness limits the usage of $\mathrm{Al}_{2} \mathrm{O}_{3}$ for full length cutting operations. ${ }^{[7]}$ Recently, some of the researchers had suggested the usage of carbon based nanomaterials as fillers in $\mathrm{Al}_{2} \mathrm{O}_{3}$ to curtail its brittleness. ${ }^{[8,9]}$ But several studies indicated that the weak interfacial bonding between $\mathrm{Al}_{2} \mathrm{O}_{3}$ and carbon nanotube (CNT), agglomerations of CNTs and densification of nanocomposites were the big challenges while fabricating the ceramic composites. ${ }^{[8-10]}$ Thus the carbon nano tubes are not fully effective for alumina ceramics. When compared with carbon nano tubes, graphene improved mechanical strength/flexibility and specific surface area. This made graphene's dispersion far easy into the ceramic matrix..$^{[11-13]}$ Even though hot pressing and spark plasma sintering are generally used to prepare ceramic tools based on alumina materials ${ }^{[14,15]}$; both processes were having their own disadvantages. Because of the long sintering times in hot pressing sintering (HP) method, abnormal grain growth was present and becoming detrimental in enhancing the ceramic based tools properties. To overcome these problems, some researchers around the world had proposed microwave sintering to improve the efficiency and reduce the cost of 
K.I.Vishnu Vandana et al., International Journal of Emerging Trends in Engineering Research, 8(10), October 2020, 7524 - 7531

fabrication of composites. ${ }^{[16-18]}$. This resulted in a more rapid temperature distribution in a homogeneous manner throughout the materials and induced better mechanical properties into the materials along with a refined crystalline structure. ${ }^{[19-20]}$

Along with the validation of basic mechanical properties like hardness and toughness of prepared composite cutting tools, it is also very vital to recognize the wear in the tool and surface roughness of machined component for effective utilization in machining hardened steels. It is important to mention that pair of contact surfaces formed between tool and work piece material while machining the component. This contact promotes intense abrasion over certain portions of the cutting tool. As a result of this phenomenon, different forms of tool wear were observed. Further, the wear mechanism depends on different factors like type of work piece material, type of tool material and cutting conditions. This wear mechanism during machining of ceramic tools was studied by several authors by varying cutting speed, feed and depth of cut. Senthil et. al ${ }^{[21]}$ studied the effect of wear on the tool life of the tool made by Alumina. They concluded that Ti [C, N] mixed alumina tools had shown a better tool life than other alumina ceramic cutting tools. Moreover, Zhao ${ }^{[22]}$ carried out wear tests for ceramic tools under dry and lubricated conditions using pin on disk (steel) apparatus, and concluded that the wear rate was seen to be accelerated with the increase in the speed of the wheel. In addition to the above research, the analysis for the chips generated during machining process and classification of chips was also very important and was studied by different researchers during machining with ceramic tools. ${ }^{[23,24]}$ From the literature, it has been observed that till now no considerable amount of work has been reported on the investigation of graphene toughened alumina ceramic tool prepared by microwave sintering. Further, very limited research was conducted to study the effect of abrasive wear and surface finish of machined work pieces. Hence by considering the above studies an attempt is made here to prepare a tool using alumina graphene composite (Al-G) after employing microwave sintering process. It is well known that, the study of tool wear and surface quality of the machined sample are very much required to characterize the qualities of the machined components. Therefore, the fabricated tools are investigated for their behaviour in wear and surface quality of machined surface during machining of hardened steels. As part of experimentation, dry machining tests were conducted on two different types of steels, namely EN24 and EN36 steels, respectively with the prepared ceramic cutting tools. After machining, the wear of the tools and surface roughness $\left(R_{a}\right)$ of machined surface are determined. These values are analysed to evaluate the efficacy of proposed alumina-graphene composite ceramic tool inserts during machining.

\section{MATERIALS AND METHODS}

In the present investigation, the powders of alumina and graphene are procured from a Bangalore based company (Ad-nano technologies) is used as the matrix and reinforcement, respectively to fabricate the composite ceramic tool inserts. The as-received nominal particle size of $\mathrm{Al}_{2} \mathrm{O}_{3}$ and graphene particle are found to be equal to $300 \mathrm{~nm}$ and 3-8 $\mathrm{nm}$, respectively. During fabrication, the cutting tool inserts are prepared by reinforcing $0.35 \mathrm{wt} \%$ and $0.45 \mathrm{wt} \%$ of graphene with Alumina, as highest hardness and fracture toughness are observed at the said compositions. ${ }^{[25]}$ Mixed and well processed powders are pressed in a hydraulic press and Al-G composite samples are preapared in the required square shaped tool inserts with a dimension of $25 \times 25 \times 5 \mathrm{~mm}^{3}$. The pressed green samples are then placed in microwave furnace and were sintered in an organ atmosphere. Sintering of the samples is performed at a temperature of $1500^{\circ} \mathrm{C}$ and a holding time of $30 \mathrm{~min}$, to obtain better density for the fabricated inserts. The compositions, densities, hardness and fracture toughness values of tool materials are given in Table. 1. The fabricated composite ceramic inserts are shown in Fig. 1.

Table 1: Details of Composition and Properties of the Ceramic cutting Tools

\begin{tabular}{|c|c|c|c|c|}
\hline S.No & $\begin{array}{c}\text { Composition } \\
\text { of tool } \\
\text { with } \\
\text { Graphene } \\
\text { wt\% }\end{array}$ & $\begin{array}{c}\text { Density } \\
(\mathrm{g} / \mathrm{cc})\end{array}$ & $\begin{array}{c}\text { Hardness } \\
(\mathrm{GPa})\end{array}$ & $\begin{array}{c}\text { Fracture } \\
\text { Toughness } \\
\left(\mathrm{MPa} \mathrm{m}^{1 / 2}\right)\end{array}$ \\
\hline 1 & $\begin{array}{c}\text { Al-G }(0.35 \\
\mathrm{wt} \%)\end{array}$ & 3.96 & 19.04 & 4.32 \\
\hline 2 & $\begin{array}{c}\text { Al-G (0.45 } \\
\mathrm{wt} \%)\end{array}$ & 3.89 & 21.27 & 4.91 \\
\hline
\end{tabular}

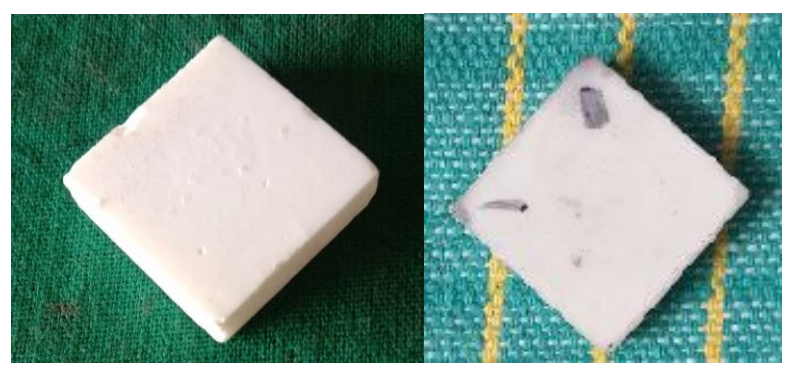

(a)

(b)

Fig. 1: Alumina-Graphene (Al-G) ceramic cutting tool inserts,

(a) $0.35 \mathrm{wt} \%$ graphene and (b) $0.45 \mathrm{wt} \%$ graphene

The machining tests are performed on a precession lathe (Indian make, SS\&SG model) using alumina-graphene 
composite ceramic tool inserts on a hardened steel work piece of grade EN24 and EN36, at different machining conditions as given in Table.2. The diameter and length of the work piece considered in this study are taken as $40 \mathrm{~mm}$ and 100 $\mathrm{mm}$, respectively.

Table 2: Table showing the conditions at which the experiments are conducted

\begin{tabular}{|c|c|c|}
\hline speed, rpm & feed, $\mathrm{mm} / \mathrm{rev}$ & depth of cut, $\mathrm{mm}$ \\
\hline $100,300,500$ & $0.3,0.5,0.8$ & $0.1,0.2,0.3$ \\
\hline
\end{tabular}

Each machining test has been conducted for 15 minutes without any cutting fluid i.e completely in dry environment. The weights of the cutting tool inserts are measured before and after the machining tests. Abrasive wear of cutting tool inserts and surface roughness of machined surfaces are measured and documented for further analysis. The wears out areas of prepared tool inserts are analyzed using scanning electron microscope.

In the present investigation, the wear rate of the fabricated ceramic cutting tool inserts are studied by conducting the experiments at the levels of the machining parameters given in Table 2. The results of this investigation are explained in the following sub-sections.

\section{RESULTS AND DISCUSSION}

Abrasive wear is highly dominant wear and is mainly observed on the flank and rake face of the cutting tools. Mechanical properties like hardness and fracture toughness predominantly control the abrasive wear. These properties are determined and analysed for different wt $\%$ of graphene reinforced alumina composite tool inserts. Abrasive wear is mainly characterized by developed grooves and ridges in the direction of sliding of the tool against machined surface. Abrasive wear can be severe when the work piece contains hard asperities and inclusions. The tool material properties and work piece surfaces are much affected by high temperatures generated during this rubbing process.

The SEM images that represent the condition of ceramic cutting tool inserts before and after the machining operation performed (at 100rpm speed , $0.3 \mathrm{~mm} / \mathrm{rev}$ feed and $0.1 \mathrm{~mm}$ of depth of cut) on $0.35 \mathrm{wt} \%$ and $0.45 \mathrm{wt} \%$ graphene reinforced alumina composites are shown in Figs. 2 and 3, respectively. Ploughed grooves observed on the tool edge (ref. to Fig. 2(b)) after machining indicates the insufficient bonding between the matrix and the reinforcement at high cutting depths with 0.35 wt $\%$ of graphene ceramic tool. This might have happened due to the relatively less hardness and fracture toughness of alumina-graphene $(0.35 \mathrm{wt} \%)$ tool insert when compared with the $0.45 \mathrm{wt} \%$ alumina-graphene tool insert [23]. Further, the ploughing and chipping of the fabricated tool inserts are also due to the poor resistance to absorb shocks and low plastic deformation ability of the ceramic material.

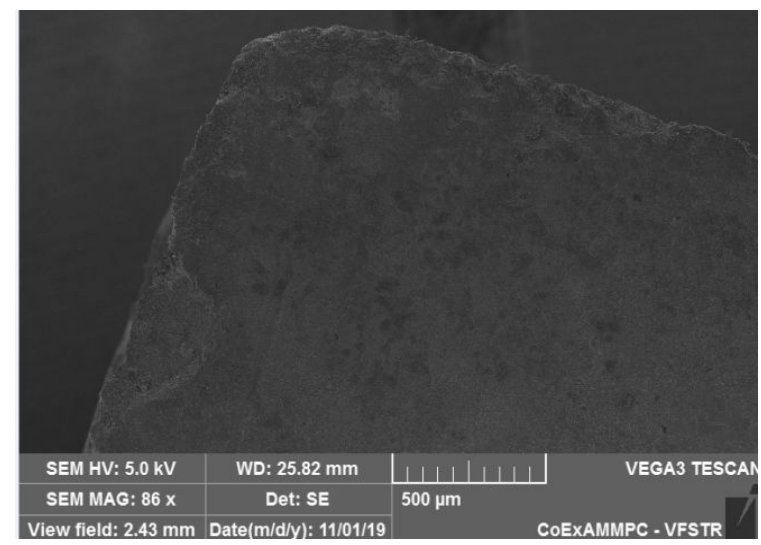

(a)

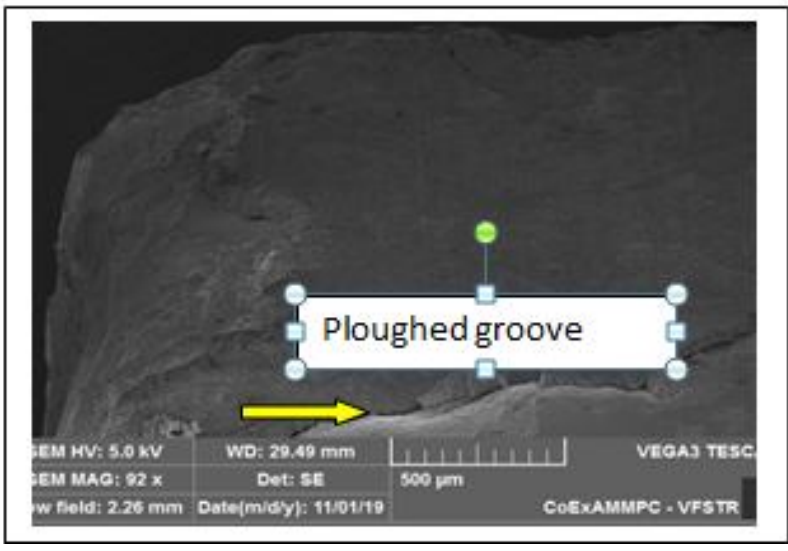

(b)

Fig. 2: Schematic diagram showing the SEM images of 0.35 wt $\%$ graphene reinforces alumina ceramic composite tool, (a) before and (b) after machining.

Figure 3 (b) shows the chipped edges on the flank side of the $0.45 \mathrm{wt} \%$ of alumina-graphene tool insert, and it indicates the failure of the tool during machining. This might be due to the vibration of the tool at a large depth of cuts. However, the amount of chipping is less on $0.45 \mathrm{wt} \%$ tool insert when compared with the $0.35 \mathrm{wt} \%$ alumina-graphene tool insert.

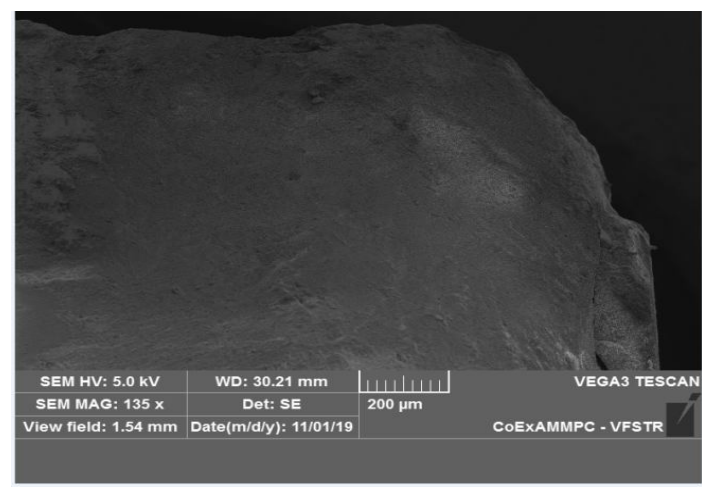

(a) 


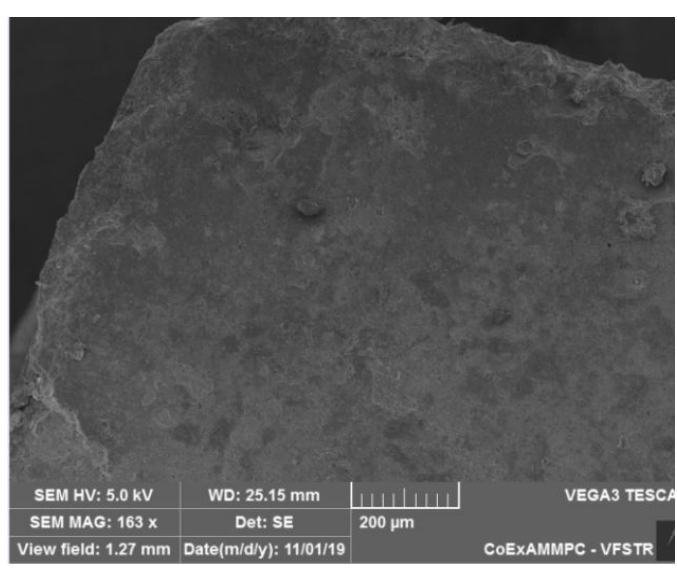

(b)

Fig. 3: Schematic diagram showing the SEM images of 0.45 wt $\%$ graphene reinforces alumina ceramic composite tool, (a) before and (b) after machining.

It is important to mention that the higher wt $\%$ of graphene in this case might have acted like a load bearing member and provided damping action during machining at relatively high depth of cuts. The higher amount of graphene in alumina-graphene $(0.45 \mathrm{wt} \%)$ tool material has also helped in enhancing the hardness and fracture toughness of the tool material.

In order to study the abrasive wear phenomenon of the fabricated composite ceramic tools, the experiments are conducted by varying speed, feed and depth of cut during machining. The cutting speed, feed and depth of cut are varied at $(100,300$ and $500 \mathrm{rpm}),(0.3,0.5,0.8 \mathrm{~mm} / \mathrm{rev})$ and $(0.1, \quad 0.2$ and $0.3 \mathrm{~mm})$, respectively. The machining operations are conducted by varying a parameter at a time after and making the other two parameters at a fixed value. Fig. 4 and Fig. 5 shows the variation of abrasive wear for EN24 and EN36 steel work pieces, respectively while using $0.35 \mathrm{wt} \%$ and $0.45 \mathrm{wt} \%$ of graphene reinforced alumina composite ceramic tools.

From Fig. 4 and Fig. 5, it is clearly evident that with the increasing speed and feed rate, wear loss per minute is also seen to be increased when machining both the EN24 and EN36 hardened steels. With the rise in the speed and feed rate, the rubbing between the tool and material is increased. The increase in the value of friction resulted in the generation of more heat between the tool and work piece. This raise in heat further results in the enhanced material loss particularly at high speeds. Therefore, it is concluded that at higher values of speeds and higher depth of cut, the weight loss per minute of the composite ceramic tools is increased. Moreover, the feed rate of the tool is also having greater influence on the weight loss of the tool when compared with the depth of cut at considered speed levels.

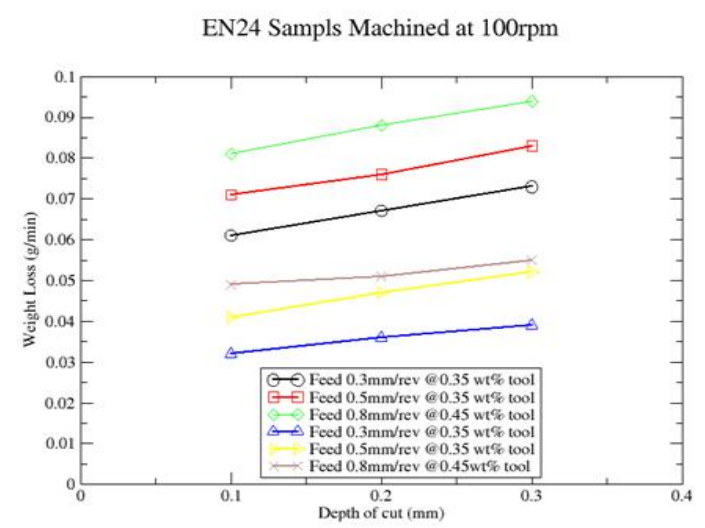

(a)

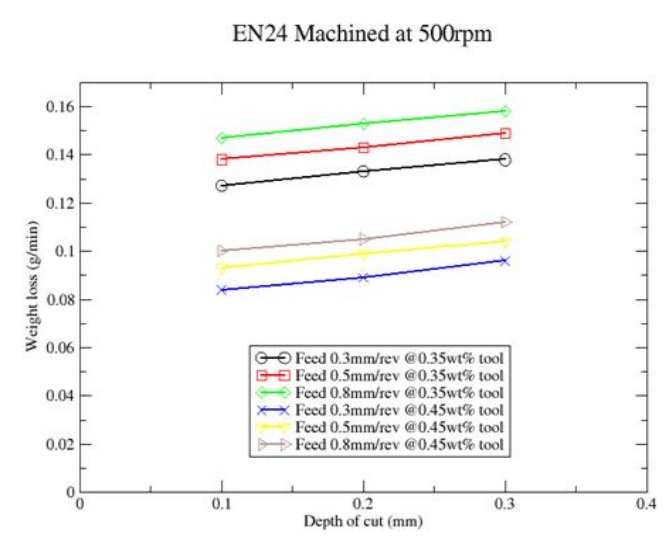

(b)

Fig. 4: Graph showing the variation of weight loss between two tools per minute for EN24 steel a) at $100 \mathrm{rpm}$ and (b) at $500 \mathrm{rpm}$

EN36 Samples machined at 100rpm

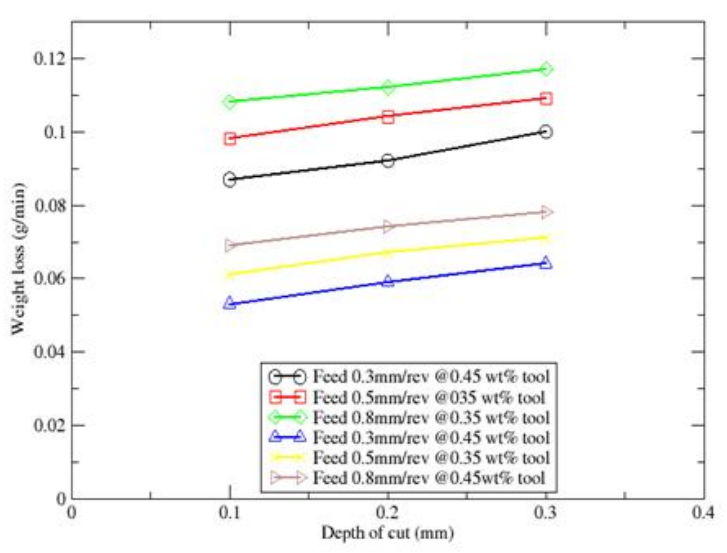

(a) 
EN36 Samples Machinedat 500rpm

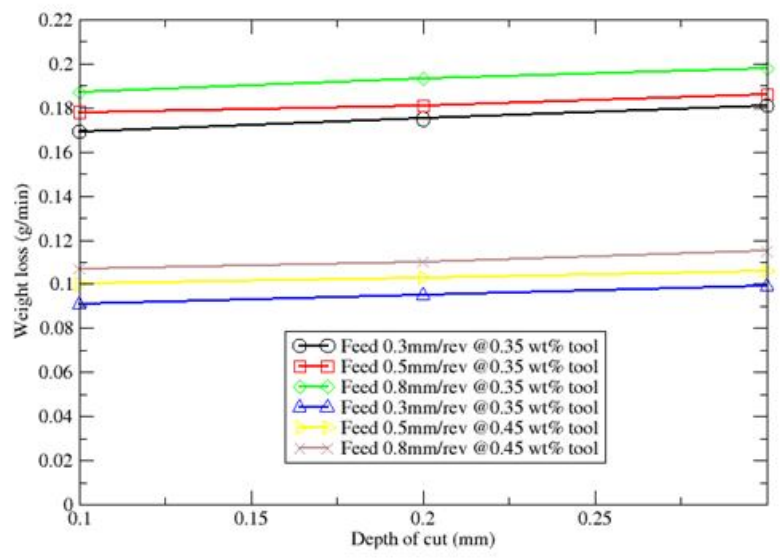

(b)

Fig. 5: Graph showing the variation of weight loss per minute between two tools for EN36 steel

(a) at $100 \mathrm{rpm}$ and (b) at $500 \mathrm{rpm}$

It was observed that Alumina tool inserts reinforced with 0.45 wt $\%$ of graphene showed $47.54 \%$ less abrasive wear than tool inserts reinforced with $0.35 \mathrm{wt} \%$ of graphene at low speed $(100 \mathrm{rpm})$, feed $(0.3 \mathrm{~mm} / \mathrm{rev})$, depth of cut $(0.1 \mathrm{~mm})$ and showed $29.11 \%$ less abrasive wear than tool inserts reinforced with $0.35 \mathrm{wt} \%$ of graphene at high speed (500rpm), feed $(0.8 \mathrm{~mm} / \mathrm{rev})$, depth of cut $(0.3 \mathrm{~mm})$ respectively, when machining on EN24 steel samples. Tool inserts reinforced with $0.45 \mathrm{wt} \%$ of graphene showed $39.08 \%$ less abrasive wear than tool inserts reinforced with $0.35 \mathrm{wt} \%$ of graphene at low speed $(100 \mathrm{rpm})$, feed $(0.1 \mathrm{~mm} / \mathrm{rev})$, depth of cut $(0.1 \mathrm{~mm})$ and showed $41.91 \%$ less abrasive wear than tool inserts reinforced with $0.35 \mathrm{wt} \%$ of graphene at high speed (500 $\mathrm{rpm})$, feed $(0.8 \mathrm{~mm} / \mathrm{rev})$, depth of cut $(0.3 \mathrm{~mm})$ respectively, when machining on EN36 steel samples.

Finally the wear is observed to be lower in alumina-graphene (0.45 wt $\%)$ composite tool inserts when compared to alumina-graphene $(0.35 \mathrm{wt} \%)$ composite tool inserts when machined on both EN24 and EN36 steel samples. But the wear is slightly higher in case of both tool inserts when machined on EN36 steel samples when compared with EN24 steel samples. The rise in the wear of cutting tool inserts can be attributed to high hardness of EN36 steels. Totally less wear is observed in alumina-graphene $(0.45 \mathrm{wt} \%)$ composite tool inserts when compared to alumina-graphene $(0.35 \mathrm{wt} \%)$ composite tool inserts when machined on both type of steels. The reason for less wears in case of alumina-graphene $(0.45$ wt $\%$ ) composite tool may be attributed to higher wt $\%$ of graphene in the composite. The alumina matrix surrounded by graphene particles may be acted as a lubricant in case of alumina-graphene $(0.45 \mathrm{wt} \%)$ composite tool and reduced the wear.
The quality of surface attained during the hard turning process is also very much close to that of the surface quality obtained after employing grinding process. Surface roughness or surface finish of the machined surface is one of the vital factors affecting the application of alumina ceramic cutting tool. The results of surface roughness values obtained after machining EN24 and EN36 steels using the fabricated composite ceramic tools is presented in Figs. 6 and 7, respectively. The surface roughness values of EN24 and EN36 steel samples measured using surface roughness tester SJ-210 (MITUTOYO make). Surface roughness values are taken at three different positions on each machined surface and the average value of the said readings is used to plot the graphs.

EN24 samples Machined at 100rpm

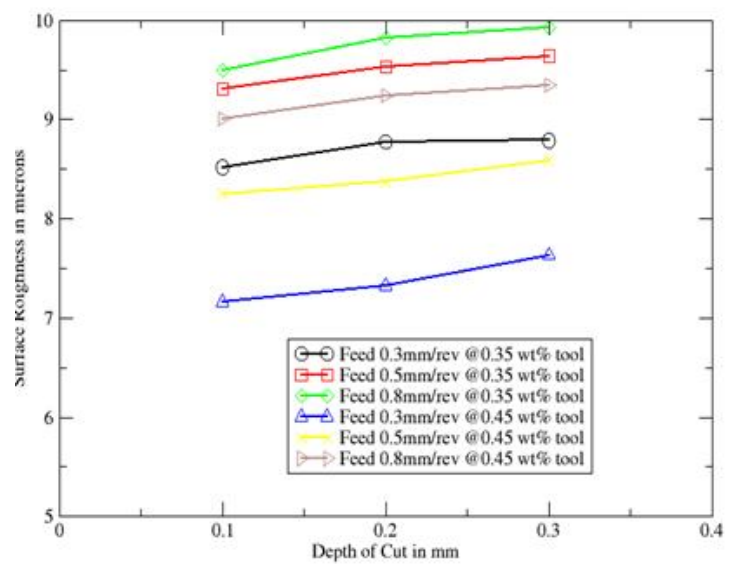

(a)

EN24 Sample Machined at 500rpm

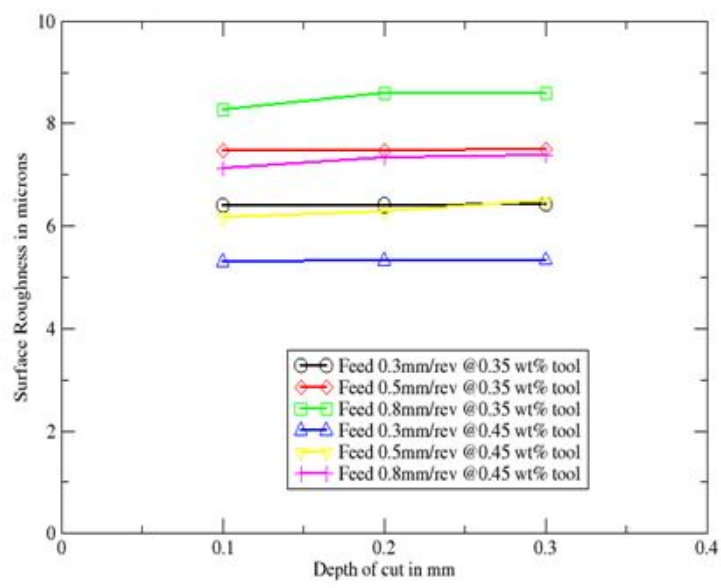

(b)

Fig. 6: Graph showing the variation of surface roghness for EN24 steel samples machined with two tools (a) at $100 \mathrm{rpm}$ and (b) at $500 \mathrm{rpm}$

It is clearly evident that the surface roughness values of both EN24 and EN36 steel samples are reduced notably with the 
increased cutting speed when machined with both $0.35 \mathrm{wt} \%$ and $0.45 \mathrm{wt} \%$ alumina-graphene ceramic cutting tools. An increasing trend in surface roughness is observed on both the machined surfaces when increasing the feed rate and keeping the cutting speed and depth of cut at a constant value. This is due to the vibrations induced the cutting tool at the higher feed rate. This effect results in inducing the larger feed marks on the machined surface. Further, it also helps in increasing the surface temperature of the work and tool materials, which facilitates more particles pulling from the work piece material. Moreover, the effect of depth of cut on surface roughness of machined surfaces is seems to be minimum when compared with the cutting speed and feed rate effect.

EN36 Samples Machined at 100rpm

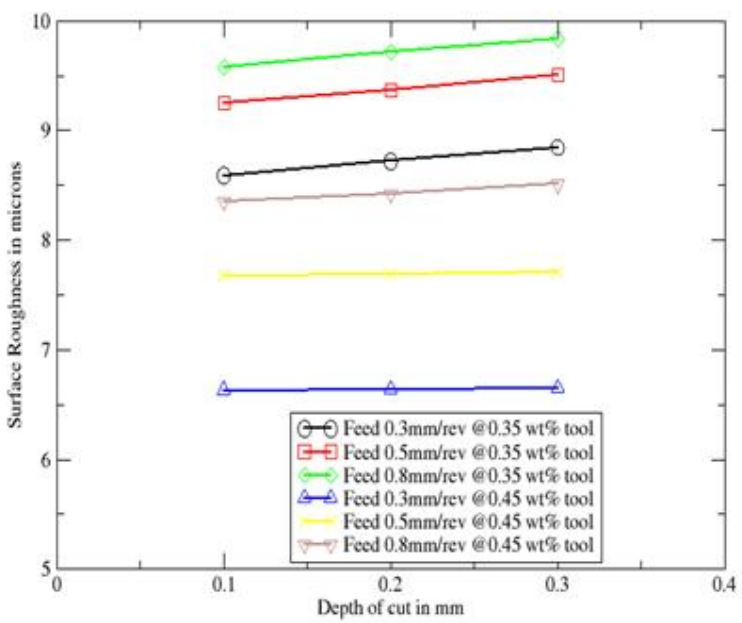

(a)

EN36 Samples machined at 500rpm

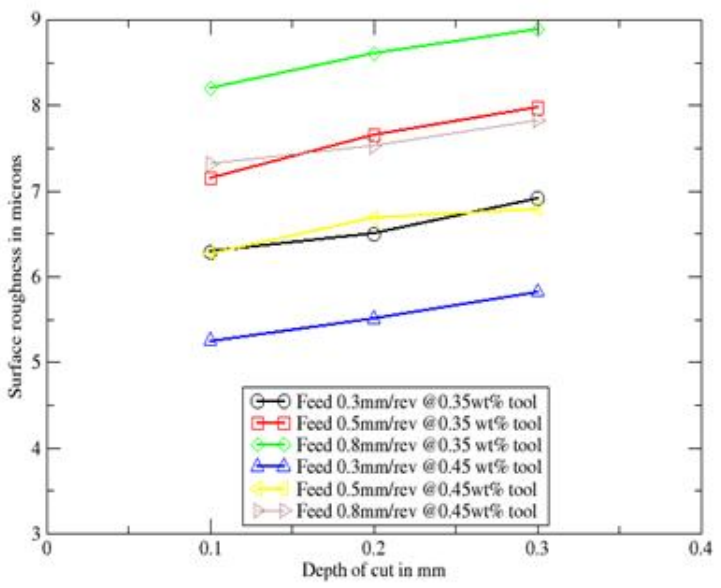

(b)

Fig. 7: Graph showing the variation of surface roghness for EN36 steel samples machined with two (a) at $100 \mathrm{rpm}$ and (b) at $500 \mathrm{rpm}$
An increasing trend in surface roughness was observed when depth of cut was increased in both the samples when machined with the fabricated tool inserts. But the rate of increase of surface roughness is less in case of both the EN24 and EN36 steel samples, when machined with $0.45 \mathrm{wt} \%$ alumina-graphene ceramic cutting tool inserts than the surfaces machined with $0.35 \mathrm{wt} \%$ alumina-graphene ceramic cutting tool inserts. It is also important to note that alumina tool inserts reinforced with $0.45 \mathrm{wt} \%$ of graphene, yielded $20 \%$ less surface roughness values than the samples machined with tool inserts reinforced with $0.35 \mathrm{wt} \%$ of graphene at low speed $(100 \mathrm{rpm})$, feed $(0.3 \mathrm{~mm} / \mathrm{rev})$, depth of cut $(0.1 \mathrm{~mm})$. Moreover, it is to be noted that the machined samples has shown $26.66 \%$ less surface roughness at high speed $(500 \mathrm{rpm})$, feed $(0.8 \mathrm{~mm} / \mathrm{rev})$ and depth of cut $(0.3$ $\mathrm{mm}$ ), when machining on EN24 steel samples. Tool inserts reinforced with $0.45 \mathrm{wt} \%$ of graphene has resulted in $20.25 \%$ less surface roughness values than the tool inserts reinforced with $0.35 \mathrm{wt} \%$ of graphene at low speed $(100 \mathrm{rpm})$, feed $(0.3$ $\mathrm{mm} / \mathrm{rev})$, depth of cut $(0.1 \mathrm{~mm})$. Moreover, the surface roughness values are seen to be $48.38 \%$ less at high speed $(500 \mathrm{rpm})$, feed $(0.8 \mathrm{~mm} / \mathrm{rev})$ and depth of cut $(0.3 \mathrm{~mm})$, respectively, when machining on EN36 steels. Finally it can be observed that both EN24 and EN 36 steel samples machined with $0.45 \mathrm{wt} \%$ alumina-graphene ceramic cutting tool inserts have shown a significantly low surface roughness values when compared with the surfaces machined with 0.35 wt $\%$ alumina-graphene cutting tool inserts at all cutting conditions.

\section{CONCLUSIONS}

In the present manuscript, an attempt has been made to fabricate and study the wear and machining characteristics of $0.35 \mathrm{wt} \%$ and $0.45 \mathrm{wt} \%$ graphene reinforced alumina composite ceramic tools while machining EN24 and EN36 steel work piece material. The following conclusions are drawn from the said experimental investigations:

1. Both the composite ceramic inserts are capable of machining two different variants of hard steels, namely EN 24 and EN36 steels, respectively.

2 . With the increase in the cutting speed, the abrasive wear is also seen to be increased. However, the abrasive wear in 0.45 wt $\%$ Al-G cutting tool insert is found to be lower when compared with the $0.35 \mathrm{wt} \% \mathrm{Al}-\mathrm{G}$ cutting tool insert while machining both the types of steels.

3. Surface roughness of Al-G $(0.45 \mathrm{wt} \%)$ ceramic cutting tool machined samples is less when compared with the surface roughness of $\mathrm{Al}-\mathrm{G}(0.35 \mathrm{wt} \%)$ ceramic cutting tool machined samples in all the cases of cutting speed, feed and depth of cut. Low values of wear and surface roughness of machined surfaces are encouraging the Al-G $(0.45 \mathrm{wt} \%)$ ceramics cutting tools for machining of hardened steels. 
K.I.Vishnu Vandana et al., International Journal of Emerging Trends in Engineering Research, 8(10), October 2020, 7524 - 7531

\section{REFERENCES}

[1] O.G. Selivanov, E.S. Pikalov and A.S. Kolosova. Ceramic material for fluoride and phosphate ions removal from natural

water, Vol. 8, No.5, pp. 1732-1735, May 2020•

[2] Angham Hazim, Hayder M. Abduljalil and Ahmed Hashim. Structural, Electronic, Optical Properties and Antibacterial Application of Novel(PMMA-Al2O3-Ag) Nanocomposites for Dental Industries aplications, International Journal of Emerging Trends in Engineering Research, Volume 7, No.8, pp. 104-122, August 2019.

[3] G. Katarina. Ceramics Tool Materials with Alumina Matrix, Machine Design, ISSN 1821- 1259, pp. 367-372, 2010.

[4] A.Senthil Kumar, A. Raja Duraia and T. Sornakumar. Wear behaviour of alumna ceramic cutting tools on machining steels, Tribology International, Vol. 39, pp. 191-197, 2006.

[5] G.Brandt. Ceramic cutting tools, State of the art and development trends, Mater Technology, Vol. 14, pp. 17-22, 1999.

[6] A.Senthil Kumar, A. Raja Duraia and T. Sornakumar. Machinability of hardened steel using alumina based ceramic cutting tools, International Journal of Refractory metals and hard materials, Vol. 21, pp. 109-117, 2003.

[7] L.Osayande, I. Okoli. KIC enhancement for alumina system: a review, Int. J. App. Ceram. Technol., Vol. 5, pp. 313-323, 2008.

[8] J.Llorca, M. Elices and J.A. Celemin. Toughness and microstructural degradation at high temperature in SiCfiber-reinforced ceramics, Acta Mater., Vol. 46, pp. 2441-2453, 1998.

[9] F.Yongqing, Y.W. Gu and D.Hejun. SiC whisker toughened Al2O3-(Ti,W)C ceramic matrix composites, Scripta Mater., Vol. 44, 2001, pp. 111-116, 1998.

[10] D.E.Garcia, S. Schicker, J. Bruhn, R. Janssen and N. Claussen. Processing and mechanical properties of pressureless-sintered niobium-alumina-matrix composites, J. Am. Ceram. Society, Vol. 81, pp. 429-32, 1998.

[11] A.Nieto, B.Ankita, B. Lahiri, and C.Zang. Graphene reinforced metal and ceramic matrix composites: a review, Vol. 62, pp. 241-302, 2017.
[12] M.Michalkova, M. Kasiarova and P.Tatarko. Effect of homogenization treatment on the fracture behaviour of silicon nitride/graphene nanoplatelets composites, Journal of European Ceram Society, Vol. 98, pp. 3291-3299, 2014.

[13] O.Tapaszto, L.Tapaszto and Marko. Dispersion patterns of graphene and carbon nanotubes in ceramic matrix composites, Chemical Physics Letters, Vol. 511, pp. 340-343, 2011.

[14] Z.B.Yin, C.Z.Huang, B.Zou, H.L Liu and H.T. Zhu. Wang, J. Study of the mechanical properties, strengthening and toughening mechanisms of Al2O3/TiC micro-nanocomposite ceramic tool materials, Mater. Sci. Eng. A. Vol. 577, pp. 9-15, 2013.

[15] H.Porwal, S. Grasso and M.J .Reece. Review of graphene-ceramic matrix composites, Adv. Appl. Ceram., Vol. 112, pp. 443-454, 2013.

[16] R. Benavente, M.D. Salvador, F.L.Penaranda-Foix, E.Pallone and A.Borrell. Mechanical properties and microstructural evolution of alumina-zirconia nanocomposites by microwave sintering, Ceram. Int., Vol. 40, pp. 11291-11297, 2014.

[17] Y. Cheng, S.S. Sun and H.P. Hu. Preparation of Al2O3/TiC micro-composite ceramic tool materials by microwave sintering and their microstructure and properties, Ceram. Int., Vol. 40, pp. 16761-16766, 2014.

[18] Z.B. Yin, J.T Yuan, Y.Cheng, C. Wang, Z.H.Wang and X.Q. Hu. Microstructure and mechanical properties of $\mathrm{Al} 2 \mathrm{O} 3 / \mathrm{Ti}(\mathrm{C}, \mathrm{N})$ ceramic tool materials by one-step and two-step microwave sintering, Mater. Sci. Eng. A, Vol. 670, pp. 159-165, 2016.

[19] R.Roy, D. Agrawal, J.C. Amp and S. Gedevanishvili. Full sintering of powdered-metal bodies in a microwave field, Nature, Vol. 399, pp. 304-309, 1999.

[20] L.Acevedo, S. Usón and J. Uche. Exergy transfer analysis of microwave heating systems, Energy, Vol. 68, pp. 349-363, 2014.

[21] A.Senthil Kumar, A. Raja Duraia and T. Sornakumar. The effect of tool wear on tool life of Alumina based ceramic cutting Tools while machining hardened martensitic stainless steels, Journal of Material Processing Technology, Vol. 173, pp. 151-156, 2006.

[22] Z. Xingzhong, J. Liu, U. Baoliang Zhu, H. Miao and Z. Luo. Tribological characteristics of Si3N4 ceramic sliding on stainless steel, Wear, Vol. 1997, pp. 76-82, 2006. 
[23] X.Tiana, J. Zhao, X. Wang, H. Yanga and Z. Wang. Performance of Si3N4 / (W, Ti) C graded ceramic tool in high-speed turning iron-based superalloys, Ceramics International Vol. 44, Issue 13, pp. 15579- 15587, 2018.

[24] S.Ranjan Dasa, A. Panda and D. Dhupal. Hard turning of AISI 4340 steel using coated carbide insert: Surface roughness, tool wear, chip morphology and cost estimation, Science Direct Materials Today, Proceedings, Vol. 5, pp. 6560-6569, 2018.

[25] K.I.Vishnu Vandana and K.N.S. Suman. Hardness and Fracture Toughness of Ceramic Composite Using Experimental and Analytical Methods, International Journal of Engineering and Advanced Technology (IJEAT) ISSN: 2249 - 8958, Vol. 9, Issue-2, pp. 5250-5254, 2019. 